\title{
Congressional Fellows: A Perspective
}

At the beginning of 1995, the Materials Research Society and the Optical Society of America announced ${ }^{1}$ the inauguration of a jointly sponsored Congressional Science and Engineering Fellowship Program. A total of 25 candidates applied thereafter, either directly or through a dual application opportunity offered in conjunction with analogous programs sponsored by the American Institute of Physics and the American Physical Society. In May, five finalists were interviewed by a joint selection committee, and in June the selection of Kelly $S$. Kirkpatrick as the first MRS/OSA Fellow was announced. ${ }^{2}$ Readers of MRS Bulletin and Optics \& Photonics News as well as others who follow activities of professional societies and science policy are certain to learn more about the activities of our Fellow and the policy milieu in which she will work during her one-year term. Here, some background is offered on the Congressional Fellow Program and why MRS in particular decided to contribute in this way.

Congressional fellow programs date back more than 20 years, and have been insightfully reviewed in a number of publications. ${ }^{3}$ Each of the four parties involved in the fellow program derives benefit.

The fellow's principal immediate benefit is education. The fellow learns the ways of the legislative process including how the federal budgeting and appropriations processes work, how proposed legislation is drafted, how it works its way to and through committees and committee hearings, and is finally acted on by Congress. Education also accumulates about the agencies of the Executive Branch and their interplay with Congress. The means by which and extent to which sound technical advice and political considerations interplay over any particular technically-based issue is not always obvious, and fellows get to see this up close. Those in the fellow role will have already demonstrated an interest in the policy arena. After the fellow year, they may well choose to stay in Washington or may find themselves in government/policy-related positions in the private sector. In either case, their opportunities for a career related to government and science policy and their value to prospective employers are enhanced by having served as a fellow.

Members of Congress, congressional committees, and their respective staffs are also immediate beneficiaries of the fellow program. A fellow normally does not function as a "consultant," but rather as someone who brings a general appreciation for science and technology and has an ability to digest and critically distill technical information to an office where the fellow is probably the only individual so endowed. Attach this to an ability to present technical issues understandably to nonscientists and the office with a fellow is well equipped to define positions on technical issues, to access the broader community of experts, to plan hearings with an appropriate slate of witnesses, and so forth. More than free labor for constituent communications and speech writing (aspects not unimportant, especially in today's downsized congressional offices), the fellow brings a much needed perspective on and appreciation for the science and engineering content of issues that permanent staffs have neither time nor resources to routinely acquire in other ways. Often fellows maintain relationships with staff long after the fellows' tenures and are called on for counsel on technical matters.

The sponsors of fellows, usually professional societies like MRS and OSA, clearly benefit too, but in less immediately measurable ways. During a fellow's term, direct interaction with the fellow is strictly constrained. As representatives of the offices for which they work, fellows may participate in policy forums of professional organizations including their own sponsor. They may author articles of a tutorial nature that describe the workings of government. But an "arms-length" relationship is maintained over substantive matters pending before government bodies because a fellow is in no sense a lobbyist and is not in Washington as the representative of any organization, particularly those that may legitimately be viewed as special-interest groups in a science policy debate. Sponsoring societies may naturally feel comfortable knowing that individuals with expertise in their respective technical areas are available on the "Hill" even when no advocacy on behalf of the societies is involved.

Former fellows, on the other hand, frequently serve their sponsoring organizations as committee members and in leadership roles where their special government experience guides society activities related to policy. Sponsors that began their programs many years ago now have a valuable collective resource in the alumni(ae) of their fellow programs. This resource goes far beyond the simple sum of individual fellow terms, for just to per- form their fellow-year tasks, fellows have had to network extensively with all the members of their class. It is this broader base that amplifies this resource for a program sponsor and expands over time.

Ultimately, the technical community as a whole benefits. Despite the testimony of expert witnesses, the findings of prestigious commissions, the briefings from agencies, and the official statements of professional organizations such as MRS and OSA, science and the scientist are underrepresented in the halls of Congress. The friends of science in Congress have repeatedly prodded the technical community to speak up and get involved. They warn that as other more vocal interest groups make their cases, the silence of science will lead to drastic shrinkage in its government support. This message is not new. Calls like this a decade ago, directed at the field of materials research, instigated the National Academies' Materials Science and Engineering Study. The fact is that materials scientists in general do not respond robustly to these challenges. Regardless of why the majority in our community is too reticent to get involved, it is fortunate that a few among us find the prospect of science policy involvement attractive. Congressional Science and Engineering Fellows are such a group. Societies that help the fellows pursue this path are in actuality also responding to the call for greater community involvement in the science policy and legislative process-an endeavor which will benefit us all.

ELTON N. KAUFMANN

Elton N. Kaufmann is chair of the subcommittee for the MRS Congressional Fellow Program under the Public Affairs Committee.

1. MRS Bulletin (January, 1995) p. 11; and Optics \& Photonics News (February, 1995) p. 15.

2. MRS Bulletin (August, 1995) p. 64; and Optics \& Photonics News (September, 1995).

3. M.L. Telson and A.H. Teich, "Science Advice to the Congress: The Congressional Science and Engineering Fellows Program," in Science and Technology Advice to the President, Congress and Judiciary, edited by W.T. Golden (Pergamon Press, New York, 1992) pp. 447-452; "Wanted Policy Wonks with PhDs," Science 258 (27 November 1992) p. 1,510; "20th Anniversary of Congressional Fellowship Program," Science 261 (27 August 1993) p. 1,190; D. Moore, APS News (March 1995) p. 2; M. Rubin, ASME News (May 1991) p. 2; "Congressional Fellow Absorbs Unique 'Culture' of Capitol Hill" including remarks of B. Hammer, APS News (November 1994) p. 6; and K.B. Taylor, GSA Today (July 1992) p. 148, (January 1993) p. 6. 